\title{
A case of ruptured mucinous cystadenoma of the pancreas with recurrence-free survival for 8 years
}

\author{
Atsuro Fujinaga ${ }^{1 *}$, Teijiro Hirashita', Yukio Iwashita', Hiroaki Nakanuma', Kazuhiro Tada', Takashi Masuda', \\ Yuichi Endo', Masayuki Ohta ${ }^{1}$, Hideki Ono ${ }^{2}$, Kazunari Murakami ${ }^{3}$ and Masafumi Inomata ${ }^{1}$
}

\begin{abstract}
Background: Pancreatic mucinous cystic neoplasm (MCM) presenting with rupture is extremely rare, and very few studies have followed up patients over the long term after ruptured mucinous cystadenoma (MCA). We report a case of ruptured MCA of the pancreas with recurrence-free survival for 8 years.

Case presentation: A 28-year-old Japanese woman was admitted to the emergency department of a local hospital after experiencing acute abdominal pain. Abdominal computed tomography revealed massive ascites and the presence of a cystic tumor measuring $60 \mathrm{~mm}$ in diameter in the pancreatic tail. Conservative therapy with antibiotics and abdominal drainage were performed to treat peritonitis that occurred secondary to the ruptured pancreatic cystic tumor, after which the patient's symptoms improved. The patient was referred to our department for further examination and treatment. We diagnosed a ruptured MCN and performed laparoscopic spleen-preserving distal pancreatectomy. Histopathological findings revealed ovarian-type stroma, which tested positive for estrogen and progesterone receptors by immunohistochemistry. The histopathological diagnosis was MCA. The postoperative course was uneventful, and the patient remains alive without any evidence of recurrence at 8 years postoperatively.

Conclusion: A good prognosis is possible even in cases of ruptured MCA. Because of the risk of peritoneal dissemination after ruptured MCA, long-term follow-up is important.
\end{abstract}

Keywords: Mucinous cystadenoma of the pancreas, MCA, Rupture

\section{Background}

Pancreatic mucinous cystic neoplasm (MCN) is characterized by mucin-producing columnar epithelium and ovarian-type stroma. MCN occurs almost exclusively in women aged $40-60$ years. MCN is often localized to the pancreatic body or tail without affecting the pancreatic ducts [1]. Ruptured mucinous cystadenoma (MCA) is extremely rare, and very few studies have followed up patients over the long term after ruptured MCA. We report a case of ruptured MCA of the pancreas with recurrence-free survival for 8 years.

\footnotetext{
* Correspondence: a-yoshimura@oita-u.ac.jp

${ }^{1}$ Department of Gastroenterological and Pediatric Surgery, Faculty of

Medicine, Oita University, Idaigaoka 1-1, Hasama-machi, Oita 879-5593, Japan Full list of author information is available at the end of the article
}

\section{Case presentation}

A 28-year-old Japanese woman was admitted to the emergency department of a local hospital after experiencing acute abdominal pain. Computed tomography (CT) imaging revealed massive ascites and the presence of a cystic tumor measuring $60 \mathrm{~mm}$ in diameter in the pancreatic tail (Fig. 1a). Conservative therapy with antibiotics and abdominal drainage were performed to treat peritonitis that occurred secondary to the ruptured pancreatic cystic tumor, after which the patient's symptoms improved. Levels of amylase and carcinoembryonic antigen (CEA) in ascites were $3220 \mathrm{IU} / \mathrm{L}$ and $226.2 \mathrm{ng} / \mathrm{mL}$, respectively, and cytological findings were negative for malignant findings. The patient was referred to our department for further examination and treatment. She

\section{Springer Open}

() The Author(s). 2020 Open Access This article is licensed under a Creative Commons Attribution 4.0 International License, which permits use, sharing, adaptation, distribution and reproduction in any medium or format, as long as you give appropriate credit to the original author(s) and the source, provide a link to the Creative Commons licence, and indicate if changes were made. The images or other third party material in this article are included in the article's Creative Commons licence, unless indicated otherwise in a credit line to the material. If material is not included in the article's Creative Commons licence and your intended use is not permitted by statutory regulation or exceeds the permitted use, you will need to obtain permission directly from the copyright holder. To view a copy of this licence, visit http://creativecommons.org/licenses/by/4.0/. 


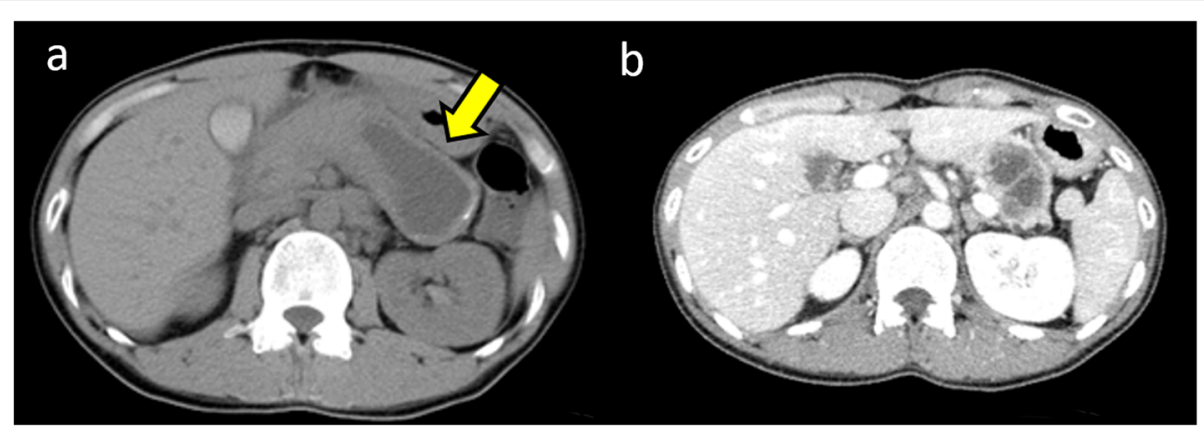

Fig. 1 Computed tomography (CT) at onset revealed the presence of a cystic tumor measuring $60 \mathrm{~mm}$ in diameter in the pancreatic tail (a, arrow). Enhanced CT in our department also revealed a tumor in the pancreatic tail with an internal septal formation (b). There was no evidence of a nodular lesion in the tumor or ascites.

had no previous medical history including pregnancy and no cigarette smoking or drinking. Her family history showed no remarkable findings.

On admission, her abdomen was flat and soft, and there was no abdominal pain. Laboratory tests showed no anemia, and liver and kidney functions were normal. Serum tumor markers CEA and CA19-9 were $0.8 \mathrm{ng} / \mathrm{mL}$ and $3620.9 \mathrm{U} / \mathrm{mL}$, respectively. Enhanced CT imaging showed a tumor measuring $60 \mathrm{~mm}$ in diameter with an internal septal formation in the pancreatic tail (Fig. 1b). There was no evidence of nodular lesion in the tumor or ascites. Magnetic resonance imaging (MRI) showed a cystic tumor with an internal septal formation present in the pancreatic tail. $\mathrm{T} 1$ - and T2-weighted imaging showed hypo- and hyperintense signals, respectively, with an unenhanced nodular lesion measuring $10 \mathrm{~mm}$ in diameter (Fig. 2a, b). Endoscopic ultrasound (EUS) also revealed a multilocular cystic tumor with nodular lesion (Fig. 3a, b). We diagnosed MCN after rupture. The tumor was close to the splenic vessels; therefore, we decided to perform a laparoscopic spleen-preserving distal pancreatectomy (SPDP) with splenic vascular resection (Warshaw's technique).

After induction of general anesthesia, the patient was positioned in the supine position. Complete exploration of the abdominal cavity revealed no ascites or peritoneal dissemination. The soft tumor was identified in the pancreatic tail (Fig. 4). To avoid rupturing the tumor, we performed fine needle aspiration (FNA) of the cystic fluid by using a balloon catheter. We aspirated $250 \mathrm{~mL}$ of yellow fluid and sutured the punctured tumor. Levels of AMY, CEA, and CA19-9 in the cystic fluid were 23, $639 \mathrm{IU} / \mathrm{L}, 203.4 \mathrm{ng} / \mathrm{mL}$, and $1,867,200 \mathrm{ng} / \mathrm{mL}$, respectively. We cut the splenic artery and vein while preserving the left gastroepiploic and short gastric vessels. Then, we cut the pancreatic body with a linear stapler and removed the tumor while preserving the spleen. Finally, we confirmed blood flow to the spleen. The operative time was $339 \mathrm{~min}$, and the blood loss was $80 \mathrm{~mL}$. The specimen was a multilocular cystic tumor measuring $80 \mathrm{~mm}$ in diameter that contained mucus. Histopathological findings revealed columnar epithelium with mild dysplasia and ovarian-type stroma, which tested positive for estrogen receptor and progesterone receptor by immunohistochemistry. The histopathological diagnosis was MCA.

The patient remained in hospital for 10 days after surgery with no postoperative complications. The patient remains alive without any evidence of recurrence at 8 years postoperatively.

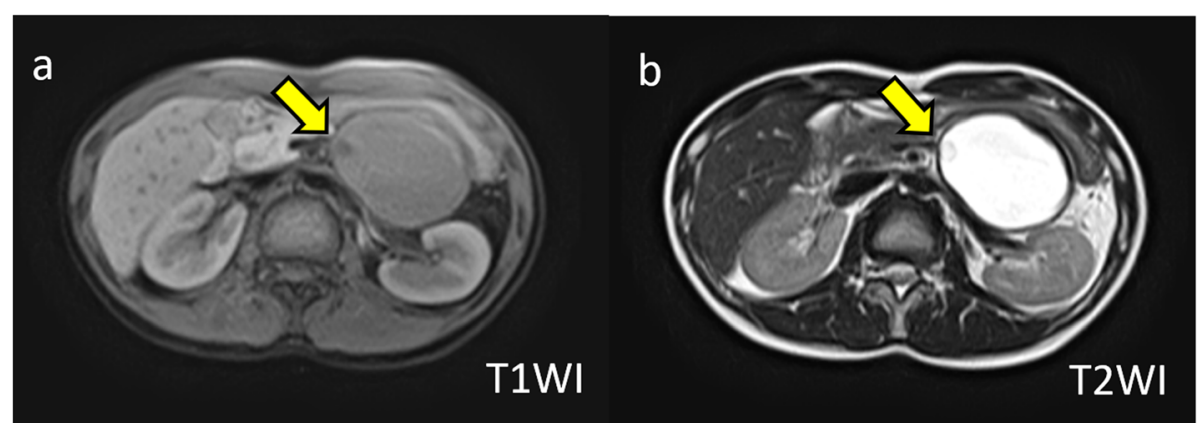

Fig. 2 a T1-weighted image. A cystic tumor with an internal septal formation was present in the pancreatic tail. The cystic lesion showed a hypointense signal with nodular lesion (arrow). b T2-weighted image. The cystic lesion showed a hyperintense signal with nodular lesion (arrow) 


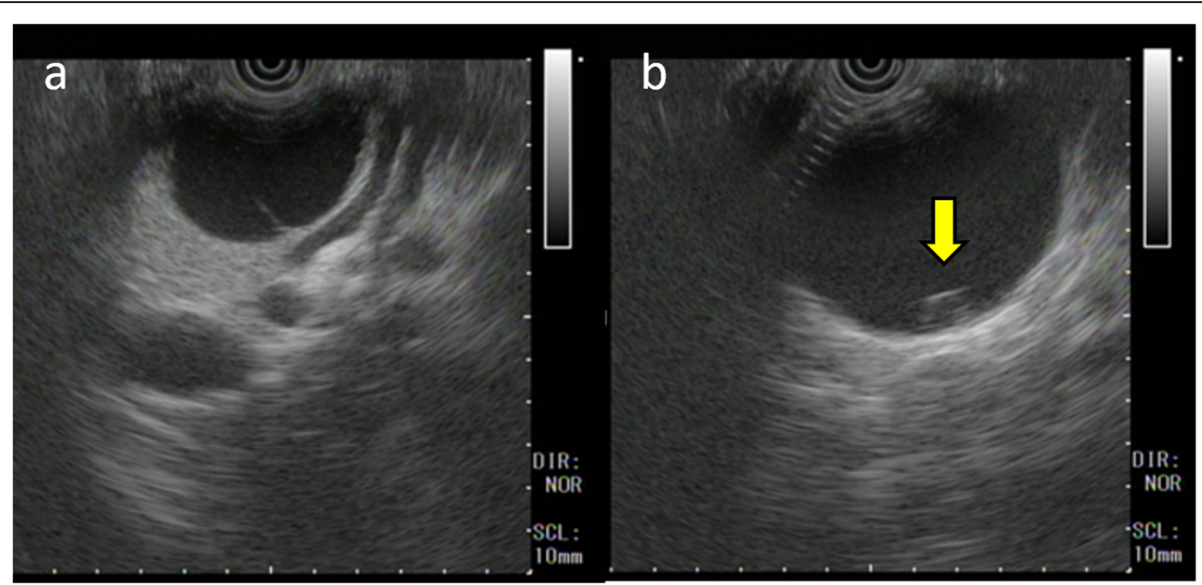

Fig. 3 Endoscopic ultrasound revealed a multilocular cystic tumor (a) with nodular lesion (b, arrow).

\section{Discussion}

Ruptured MCN is extremely rare because of its thick fibrous capsule [2]. When we searched English articles in PubMed, seven cases of ruptured MCN including our case have been reported (Table 1) [3-8]. In these reported cases of ruptured $\mathrm{MCN}$, the average patient age was 38 and all patients were women. Five cases were of mucinous cystadenocarcinoma (MCC), and two were of MCA. The average size was $116 \mathrm{~mm}$, and the tumor was located in the pancreatic body or tail in six cases. The average follow-up period was 34 months and is longest in the present case. Local recurrence occurred only in one MCC case, and all patients survived during the follow-up period. Although the prognosis of $\mathrm{MCN}$ without malignancy is good after complete resection $[1,9]$, there is a possibility of peritoneal dissemination in ruptured MCN [10], and the long-term prognosis after rupture is unknown. In the present case, the patient remains alive without any evidence of recurrence at 8

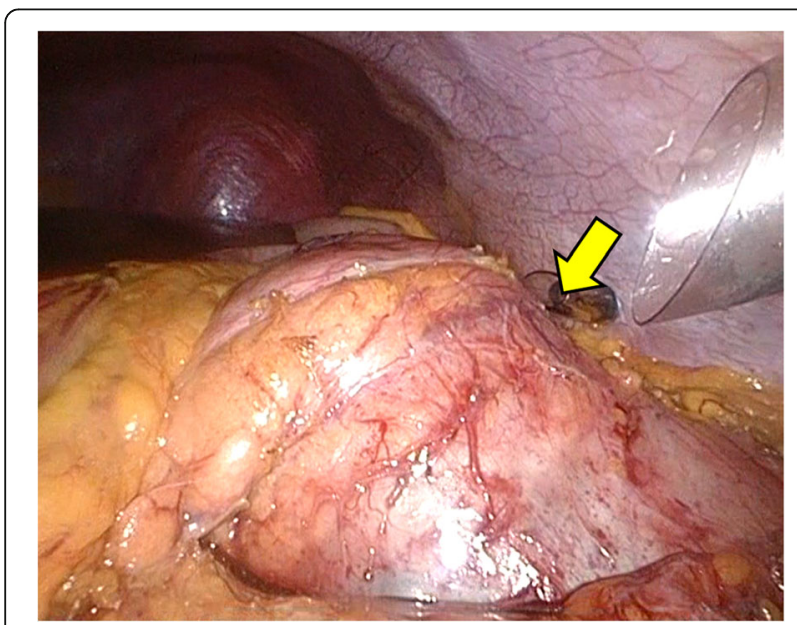

Fig. 4 A soft tumor was identified in the pancreatic tail (arrow) years postoperatively. To our knowledge, this is the longest survival time among the reported cases of ruptured MCN.

WHO defines MCN as "A benign cystic tumour composed of columnar mucin-producing epithelium supported by ovarian-type stroma" [11]. The symptoms of $\mathrm{MCN}$ develop slowly, and non-specific gastrointestinal complaints or abdominal pain are common [5]. MCN occurs almost exclusively in women aged 40-60 years and is often localized to the pancreatic body or tail without affecting the pancreatic ducts [1]. In a report considering only cases with ovarian-type stroma, 98.1\% were women with an average age of 48.1 years [9]. MCN was present in the pancreatic body or tail in $99.4 \%$ of the cases, and the average size was $65 \mathrm{~mm}$ [9]. In general, MCN does not communicate with the pancreatic ducts, but communication was observed in $18.1 \%$ of the cases $[1,9]$. The general consensus is that when $\mathrm{MCN}$ is diagnosed, it should be promptly resected regardless of whether it is malignant because of its potential for malignancy $[1,12]$. It is important not to injure the tumor during surgery [13]. Although EUS-FNA is useful for the diagnosis of pancreatic cystic tumors $[14,15]$, peritoneal dissemination has been reported in some cases after EUS-FNA [10]. Thus, the usefulness of EUS-FNA for pancreatic cystic tumors remains controversial, and it is not recommended in Japan [1]. However, EUS is considered the most useful modality for detecting nodular lesions in the cystic tumor $[1,16]$.

The cause of rupture has been reported to relate to the influence of female sex hormones on the behavior of $\mathrm{MCN}$, especially during pregnancy $[3,4,17]$. Female sex hormones may affect estrogen and progesterone receptors of the MCN and promote the production of mucus [17]. The average size of a ruptured $\mathrm{MCN}$ is $116 \mathrm{~mm}$, and it is larger than that of unruptured MCNs [9]. Therefore, the size of the MCN is thought to be related 
Table 1 Reported cases of ruptured MCNs

\begin{tabular}{|c|c|c|c|c|c|c|c|c|c|c|}
\hline & Authors (year) & $\begin{array}{l}\text { Age } \\
\text { (years) }\end{array}$ & Sex & Diagnosis & $\begin{array}{l}\text { Tumor size } \\
(\mathrm{mm})\end{array}$ & Location & $\begin{array}{l}\text { Surgical } \\
\text { procedure }\end{array}$ & $\begin{array}{l}\text { Follow-up } \\
\text { (months) }\end{array}$ & Recurrence & Outcome \\
\hline 1 & $\begin{array}{l}\text { Smithers et al. } \\
\text { [3] (1986) }\end{array}$ & 33 & $\mathrm{~F}$ & MCC & 100 & Body/tail & $\mathrm{DP}$ & Unknown & Unknown & Unknown \\
\hline 2 & $\begin{array}{l}\text { Ozden et al. } \\
\text { [4] (2007) }\end{array}$ & 32 & $\mathrm{~F}$ & MCC & 150 & Body/tail & SPDP & 12 & None & Alive \\
\hline 3 & $\begin{array}{l}\text { Bergenfeldt et al. } \\
\text { [5] (2008) }\end{array}$ & 42 & $\mathrm{~F}$ & MCC & 200 & Body & DP & 19 & None & Alive \\
\hline 4 & $\begin{array}{l}\text { Naganuma et al. } \\
\text { [6] (2011) }\end{array}$ & 32 & $\mathrm{~F}$ & MCC & 110 & Head & PD & 36 & $\begin{array}{l}\text { Local } \\
\text { recurrence }\end{array}$ & Alive \\
\hline 5 & $\begin{array}{l}\text { Imoto et al. } \\
\text { [7] (2013) }\end{array}$ & 69 & $\mathrm{~F}$ & MCC & 60 & Body/tail & DP & 2 & None & Alive \\
\hline 6 & $\begin{array}{l}\text { Haddad et al. } \\
\text { [8] (2019) }\end{array}$ & 30 & $\mathrm{~F}$ & MCA & 111 & Tail & DP & 36 & None & Alive \\
\hline 7 & Our case & 28 & $\mathrm{~F}$ & MCA & 80 & Tail & SPDP & 96 & None & Alive \\
\hline
\end{tabular}

$D P$ distal pancreatectomy, MCA mucinous cystadenoma, MCC mucinous cystadenocarcinoma, $P D$ pancreaticoduodenectomy, SPDP spleen-preserving distal pancreatectomy

to rupture. As 5 of the 7 reported cases were women aged 20 to 40 years, female sex hormones, and not only those during pregnancy, might affect tumor growth and rupture.

Regarding prognosis after rupture, recurrence occurred in the cases of MCC, and a local pattern of recurrence was present. Although no recurrence was observed in the cases of MCA, the follow-up periods were short, and the long-term prognosis remains unclear. Therefore, there is little evidence regarding prognosis after a ruptured MCN. The 5-year survival rates after complete resection of unruptured $\mathrm{MCN}$ for adenoma and adenocarcinoma were $98.8 \%$ and $86.5 \%$, respectively [9]. However, considering the malignant potential of MCN $[1,12]$ and the risk of peritoneal dissemination due the leakage of mucus [10, 18], long-term follow-up for at least 5 years on ultrasonography or CT is important to check for recurrence, including the appearance of ascites.

\section{Conclusions}

A good prognosis might be expected in patients with MCA even in those with rupture. However, there is a risk of peritoneal dissemination with rupture, and longterm follow-up is thus considered important. To our knowledge, the present patient has survived without recurrence for the longest period among the reported cases of ruptured MCN.

\section{Abbreviations}

CT: Computed tomography; DP: Distal pancreatectomy;

CEA: Carcinoembryonic antigen; EUS: Endoscopic ultrasound; EUS-

FNA: Endoscopic ultrasound-fine needle aspiration; MCA: Mucinous

cystadenoma; MCC: Mucinous cystadenocarcinoma; MCN: Mucinous cystic neoplasm; MRI: Magnetic resonance imaging; PD: Pancreaticoduodenectomy; SPDP: Spleen-preserving DP

\section{Acknowledgements}

The authors would like to thank Rise Japan, LCC (http://rise-japan.rulez.jp/) for the English language review.

Ethics approval and consent of participate

The publication of this case report was approved by the institutional ethics committee.

\section{Authors' contributions}

$A F, T H, Y I, H N, K T, T M, Y E, M O, H O$, and $K M$ drafted the manuscript. Ml gave the final approval of the version to be published. All authors read and approved the final manuscript.

\section{Funding}

This study was not funded by any grants.

\section{Availability of data and materials}

The data are not available for public access because of patient privacy concerns but are available from the corresponding author on reasonable request.

\section{Consent for publication}

The case report and publication process were explained to the patient, and she granted permission to publish the report.

\section{Competing interests}

The authors declare that they have no competing interests.

\section{Author details}

${ }^{1}$ Department of Gastroenterological and Pediatric Surgery, Faculty of Medicine, Oita University, Idaigaoka 1-1, Hasama-machi, Oita 879-5593, Japan. ${ }^{2}$ Department of Gastroenterology, Oita Prefectural Hospital, Oita, Japan. ${ }^{3}$ Department of Gastroenterology, Faculty of Medicine, Oita University, Oita, Japan.

Received: 24 January 2020 Accepted: 9 March 2020

Published online: 16 March 2020

\section{References}

1. Tanaka M, Fernández-del Castillo C, Kamisawa T, Jang JY, Levy P, Ohtsuka T, et al. Revisions of international consensus Fukuoka guidelines 2012 for the management of IPMN of the pancreas. Pancreatology. 2017;17:738-53.

2. Kimura W, Nomura T, Mizutani M, Ma J, Hirai I, Fuse A. Definition of MCN (mucinous cystic neoplasm of the pancreas) and a proposal for a new concept of MRN or MSN (mucinous round or spherical neoplasm). Hepatogastroentelogy. 2007;54:1954-6. 
3. Smithers BM, Welch C, Goodall P. Cystadenocarcinoma of the pancreas presenting in pregnancy. Br J Surg. 1986;73:591.

4. Ozden S, Haliloglu B, Iter E, Akin FT, Kebudi A, Peker O. An extremely rare cause of acute abdomen in pregnancy: ruptured pancreatic mucinous cystadenocarcinoma. Pancreas. 2007;34:474-6.

5. Bergenfeldt M, Poulsen IM, Hendel HW, Serizawa RR. Pancreatic ascites due to rupture of a mucinous cystic neoplasm. Acta Oncol. 2008;47:978-81.

6. Naganuma S, Honda K, Noriki S, Kimura S, Murakami M, Koneri K, et al. Ruptured mucinous cystic neoplasm with an associated invasive carcinoma of pancreatic head in a pregnant woman: report of a case and review of literature. Pathol Int. 2011:61:28-33.

7. Imoto A, Masuda D, Kurisu Y, Onda S, Ogura T, Takii M, et al. A case of mucinous cystadenocarcinoma of the pancreas with spontaneous rupture diagnosed by endoscopic retrograde pancreatography. Endoscopy. 2013;45: 36-7.

8. Haddad A, Sebai A, Rhaiem R, Ghedira A, Makni A. Pancreatic mucinous cystadenoma doubly complicated by acute pancreatitis and retroperitoneal rupture. J Visc Surg. 2019;156:72-4.

9. Yamao K, Yanagisawa A, Takahashi K, Kimura W, Doi R, Fukushima N, et al. Clinicopathological features and prognosis of mucinous cystic neoplasm with ovarian-type stroma: a multi-institutional study of the Japan Pancreas Society. Pancreas. 2011:40:67-71.

10. Imaoka H, Yamao K, Hijioka S, Hara K, Mizuno N, Tanaka T, et al. Pseudomyxoma peritonei arising from intraductal papillary neoplasm after surgical pancreatectomy: report of 2 cases and review of the literature. Clin J Gastroenterol. 2012:5:15-9.

11. Klöppel G, Solcia E, Longnecker DS, Capella C, Sobin LH. World Health Organization Classification of Tumors. Histological typing of tumours of the exocrine pancreas. Berlin: Springer Verlag. 1996:1-61.

12. Sugiyama M, Atomi Y, Kuroda A. Two types of mucin-producing cystic tumors of the pancreas: diagnosis and treatment. Surgery. 1997;122:617-25.

13. Nakamura Y, Matsumoto S, Tajiri T, Uchida E. Safe technique for laparoscopic distal pancreatectomy involving a large cystic tumor. J Nippon Med Sch. 2011;78:374-8

14. Brugge WR, Lewandrowski K, Lee-Lewandrowski E, Centeno BA, Szydlo T, Regan S, et al. Diagnosis of pancreatic cystic neoplasms: a report of the cooperative pancreatic cyst study. Gastroenterology. 2004:126:1330-6.

15. van der Waaij LA, van Dullemen HM, Porte RJ. Cyst fluid analysis in the differential diagnosis of pancreatic cystic lesions: a pooled analysis. Gastrointest Endosc. 2005;62:383-9.

16. Kamata K, Kitano M, Omoto S, Kadosaka K, Miyata T, Yamao K, et al. Contrast-enhanced harmonic endoscopic ultrasonography for differential diagnosis of pancreatic cysts. Endoscopy. 2016;48:35-41.

17. Kosumi K, Takamori H, Hashimoto D, Tanaka H, Abe S, Nakahara O, et al. Mucinous cystic neoplasm of the pancreas activated during pregnancy. Surg Case Rep. 2015;1:13.

18. Gupta J, Gupta A. Ruptured primary mucinous cystadenoma of spleen leading to mucinous ascites. BMJ Case Rep. 2019;12:e231212.

\section{Publisher's Note}

Springer Nature remains neutral with regard to jurisdictional claims in published maps and institutional affiliations.

\section{Submit your manuscript to a SpringerOpen ${ }^{\circ}$ journal and benefit from:}

- Convenient online submission

- Rigorous peer review

- Open access: articles freely available online

- High visibility within the field

- Retaining the copyright to your article

Submit your next manuscript at $\boldsymbol{\nabla}$ springeropen.com 